\title{
Quantitative Analysis of Lorazepam in Pharmaceutical Formulation Through FTIR Spectroscopy
}

\author{
ELAHEH KONOZ*, AMIR HOSSEIN MOHSEN SARRAFI \\ MARJANEH SAMADIZADEH, AND SAMANEH BOREIRI \\ Department of Chemistry, Faculty of Science \\ Islamic Azad University (Central Tehran Branch), Tehran, Iran \\ konozelaheh@gmail.com
}

Received 31 July 2011; Accepted 4 October 2011

\begin{abstract}
A Fourier transform infrared (FTIR) spectrophotometric method was development for the rapid, direct measurement of lorazepam in different pharmaceutical products. The method involves the off-line extraction of lorazepam with sonication and direct determination in the extract through peak height measurement in the $1704 \mathrm{~cm}^{-1}$ using a baseline correction between 1850 and $1550 \mathrm{~cm}^{-1}$. For standardization an external calibration line established from standard solutions of lorazepam in chloroform were used. The method provides a limit of detection of $0.0030 \mathrm{mg}$ per tablet $(\mathrm{n}=5)$, a relative standard deviation (RSD) of $2.65 \%$ for 5 independent measurement of standard solution at a concentration level of $1 \mathrm{mgg}^{-1}$. Result obtained by FTIR agrees with those obtained by a reference methodology based on ultraviolet spectrometry and thus the developed procedure offers a good alternative for the determination of lorazepam in commercial products.
\end{abstract}

Keywords: FTIR, lorazepam, Tablets, Pharmaceuticals, Determination.

\section{Introduction}

Lorazepam $^{1}$, 7-chloro-5-(2-chlorophenyl)-3-hudroxy-2,3-dihydro-2H-1,4-benzodiazepine-2one (Figure 1), most widely used for treatments of anxiety, relief of insomnia and sleep disturbances. They have sedative, hypnotic, muscle relaxation, anticonvulsant, and amnesic properties $^{2}$. The pharmaceutical regulatory authorities for good manufacturing practices ${ }^{3}$ require accurate analysis of finished pharmaceutical products, such as tablets and capsules, to confirm that they contain the required amount of the active ingredient. Several methods have been reported for the determination of benzodiazepines in various matrices using highperformance liquid chromatography (HPLC) $)^{4,5}$, gas chromatography-mass spectrometry $(\text { GC-MS })^{6,7}$, HPLC-MS $^{8}$, GC-tandem mass spectrometry ${ }^{9}$, micellar electrokinetic capillary chromatography $^{10}$ and voltametry ${ }^{11}$. However, at moment, few methods have been developed for determination of lorazepam using ultraviolet spectrophotometry. Thus, with the increase of the production and consumption of drugs that employ lorazepam, it becomes interesting to develop a new and less expensive spectroscopic method for its determination. However, in our knowledge only a precedent exists on the use of vibrational spectroscopy to 
solve this problem based on the quotient between the absorbance at two wavenumbers in the infrared region ${ }^{11}$. The purpose of the present study is to investigate the potential of FTIR spectrometry to quantify lorazepam in pharmaceutical preparation. The proposed analytical method in this study was performed on standard lorazepam and four different lorazepam containing pharmaceutical formulations namely lorazepam declared by the factories sample A, Loghman containing $1 \mathrm{mg}$ of lorazepam per tablet, sample B, Kimidaro containing $1 \mathrm{mg}$ of lorazepam per tablet, sample C, Zahravi containing $2 \mathrm{mg}$ of lorazepam per tablet and sample D, Abidi containing $2 \mathrm{mg}$ of lorazepam per tablet.

The main objective of this work was to develop a procedure for the fast and accurate determination of lorazepam in commercial pharmaceutical formulation by using the BeerLambert law and the reducing sample pre-treatment and providing direct measurement.

\section{Experimental}

A Perkin-Elmer spectrum 400 FT-IR Spectrometer, equipped with a modified deuterated triglycine sulphate detector and a globar IR source was employed for FTIR spectra acquisition, using a cell with $\mathrm{ZnSe}$ windows and a path length of $0.11 \mathrm{~mm}$ by averaging 25 scans per spectrum with anominal resolution of $4 \mathrm{~cm}^{-1}$.

Reference procedure measurements were carried out a perkin-Elmer Model spectrophotometer equipped with a $1 \mathrm{~cm}$ optical path quartz cell. A Bandelin Sonorex (Germany) ultrasonic water bath was used to carry out the active ingredient extraction from samples with $\mathrm{CHCl}_{3}$ for FTIR determinations.

Hettich-EBA 20 centrifuge (Germany) was employed to centrifuge samples after extraction in the proposed procedure. Lorazepam standard $(100.1 \%$, w/w) was purchased from Cambrex Profarmaco milano S.r.l. and chloroform SPS (super purity solvent) was supplied by Romil Ltd. Pharmaceuticals analyzed in this study were obtained from the Iranian market with official authorization.

\section{Reference Procedure}

Twenty tablets from each type of commercial samples were weighed and finely powdered. An accurately weighed portion of the powder, equivalent to one tablet of lorazepam, was transformed into a volumetric flask of appropriate size, based on the labeled quantity, in $\mathrm{mg}$, of lorazepam in the tablet, to obtain a solution having a concentration of about $0.1 \mathrm{mg}$ of lorazepam per $\mathrm{mL}$. Prepare a mixture of water, acetonitrile, and glacial acetic acid $(55: 45: 0.2, \mathrm{v} / \mathrm{v} \%)$ as diluent. Add a volume of diluent equal to about $50 \%$ of volume of flask, sonicate for 10 minutes and shake by mechanical means for 20 minutes. Dilute with diluent to volume. Mix and centrifuge a portion of the solution for 10 minutes at $2000 \mathrm{rpm}^{12}$.

\section{Recommended Procedure}

An accurate weight of powder, equivalent to two tablets was mixed with $10 \mathrm{~g}$ of chloroform. The sample was placed inside ultrasonic water-bath for $10 \mathrm{~min}$, in order to assess the quantitative extraction of the active ingredient. Then centrifuge the solution for $10 \mathrm{~min}$ at $5000 \mathrm{rpm}$. The extract was directly filtered into a vial using a paper whatman 42 filter. FTIR spectra from clear solution were recorded in the wavenumber range between 4000 and $850 \mathrm{~cm}^{-1}$, averaging 25 scans per spectra using a nominal resolution of $4 \mathrm{~cm}^{-1}$ and employing background spectra of the cell filled with the solvent, measured in the same instrumental conditions used for samples ${ }^{13}$. Peak area and peak height values in the interval between 1739 and $1634 \mathrm{~cm}^{-1}$, corrected with a two points baseline established between 1850 and $1550 \mathrm{~cm}^{-1}$, were employed to quantify lorazepam in samples using an external calibration line obtained with six standard solutions of lorazepam dissolved in chloroform, covering a concentration range from 0.16 to $2.14 \mathrm{mgg}^{-1}$, measured in the same conditions as samples. 


\section{Results and Discussion}

\section{FTIR Spectra of Lorazepam}

Spectra of both, samples and standards were obtained in $\mathrm{KBr}$ disks and in solution with chloroform. As depicted in Figure 1, the FTIR spectrum of a lorazepam standard diluted in potassium bromide disks exhibits numerous well defined bands, thus indicating that direct sample measurements, such as solid attenuated total reflectance (ATR) or diffuse reflectance (DRIFT), could be an alternative for fast sample analysis, but using also multivariate calibration techniques. However, the presence of high quantities of lactose and cellulose, used as excipients in the pharmaceuticals under study, prevents the direct determination of lorazepam using univariate calibration models and because of that, a previous separation of the active principle from the samples is required.

In this sense, Figure 2 shows the FTIR spectra of chloroform solutions of lorazepam standard and extracts obtained from samples, all of them obtained using a background established with the cell filled with chloroform. As can be seen, spectra of samples and standard are very similar and present several coincident vibrational bands suitable to be used for direct determination of lorazepam in commercially available tablets.

\section{FTIR Spectra of Lorazepam}

Spectra of both, samples and standard were obtained in $\mathrm{KBr}$ disks and in solution with chloroform. As it can be seen in Figure 2 the most intense band present for lorazepam standard solutions and extract is centered at $1704 \mathrm{~cm}^{-1}$ and it can be related to the presence of a carbonyl group $(\mathrm{C}=\mathrm{O})$. Other less intense bands that are located at 1326 and $1130 \mathrm{~cm}^{1}$ could be associated to the in plane $\mathrm{C}-\mathrm{H}$ bending vibrations of the benzene ring interacts with various ring $\mathrm{CC}$ vibrations ${ }^{14}$.

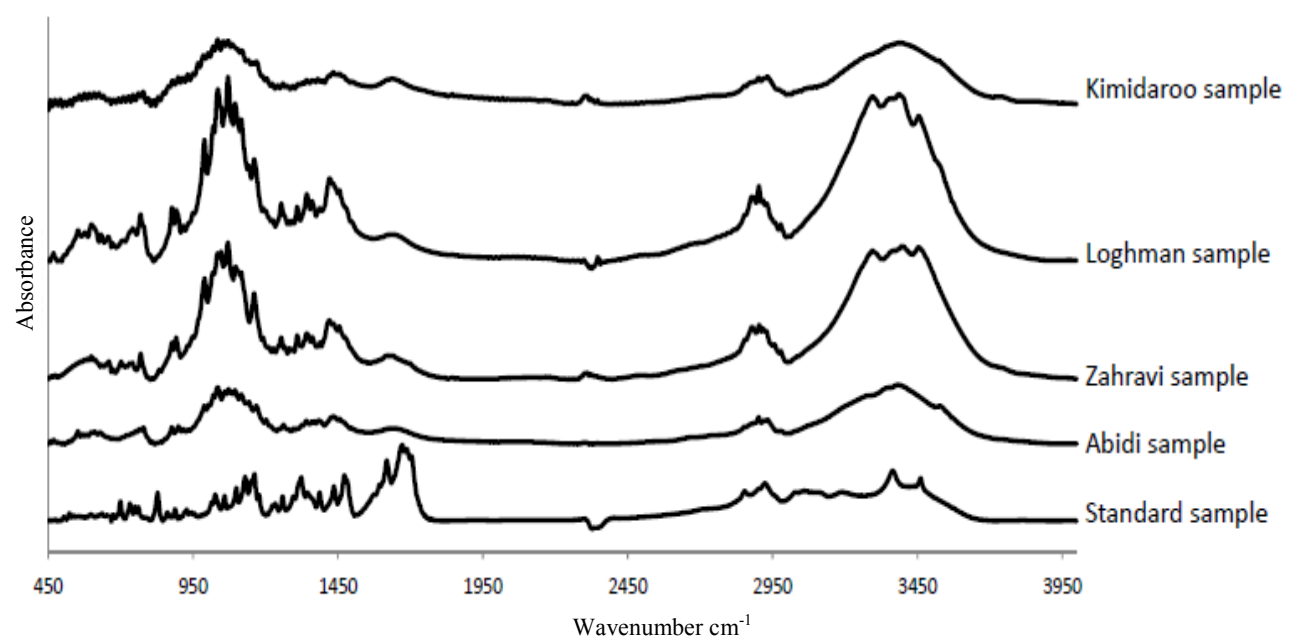

Figure 1. FTIR spectra, in $\mathrm{KBr}$ disks of lorazepam standard and four pharmaceuticals used in this study. Note: spectra were shift on the absorbance axis to clearly show their bands. Instrumental conditions: 25 scans, $4 \mathrm{~cm}^{-1}$ nominal resolution. 


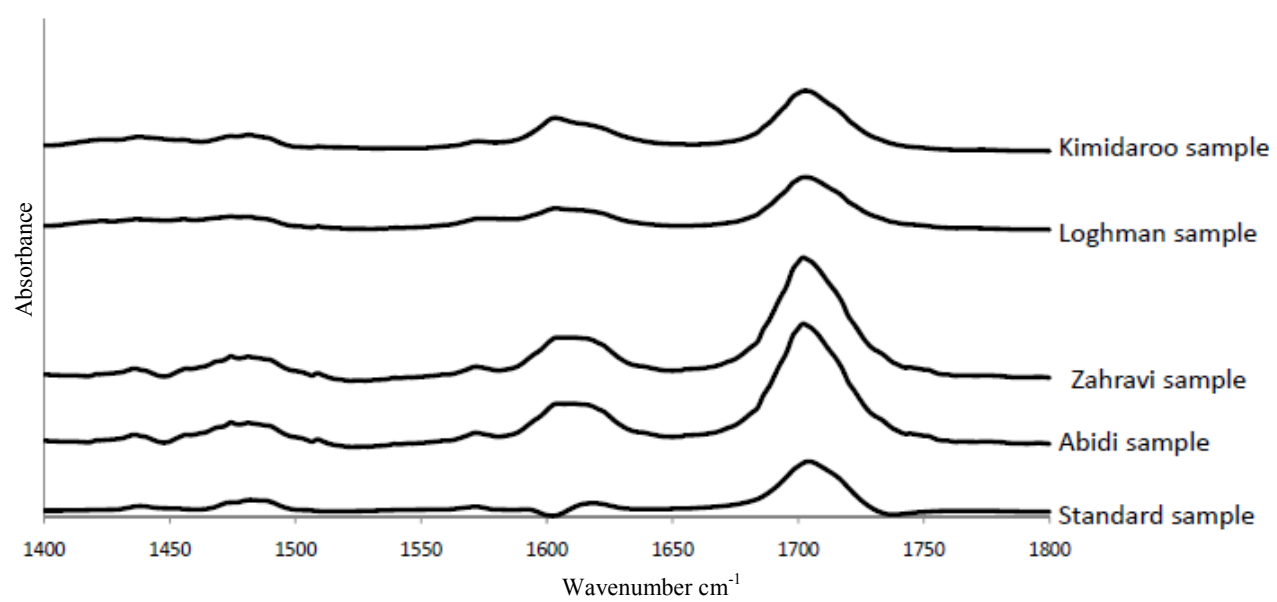

Figure 2. FTIR spectra of lorazepam standard in chloroform at a concentration of $0.16 \mathrm{mgg}^{-1}$ and extracts of each one of the four pharmaceuticals assayed. Instrumental conditions: 25 scans averaged per spectra, $4 \mathrm{~cm}^{-1}$ nominal using a background of the cell filled with chloroform. Not: spectra were shift on the absorbance axis to clearly show their bands.

\section{Effect of Instrumental Conditions}

The effect of the number of cumulated scans and the spectral resolution employed for data acquisition were evaluated in order to improve the measurements conditions. With this purpose a mono parametric study was performed. In this sense the number of cumulated scans per spectrum was modified from 5 to 70 , working with a fixed spectral resolution of $4 \mathrm{~cm}^{-1}$ and also the spectral resolution varied from 2 to $8 \mathrm{~cm}^{-1}$ averaging 25 scans.

Figure 3 shows, working with peak height values in the $1704 \mathrm{~cm}^{-1}$ corrected with two points baseline established between 1850 and $1550 \mathrm{~cm}^{-1}$, when 25 and 70 scans were cumulated, the most intense and precise results were achieved, but the time required for spectrum collection was three times higher for 70 scans that required for 25 . Thus, in order to ensure a compromise between time consumption for developing the whole procedure, sensitivity, and precisions, 25 scans were selected, that involve a measurement time of $6 \mathrm{~s}$ per spectrum.

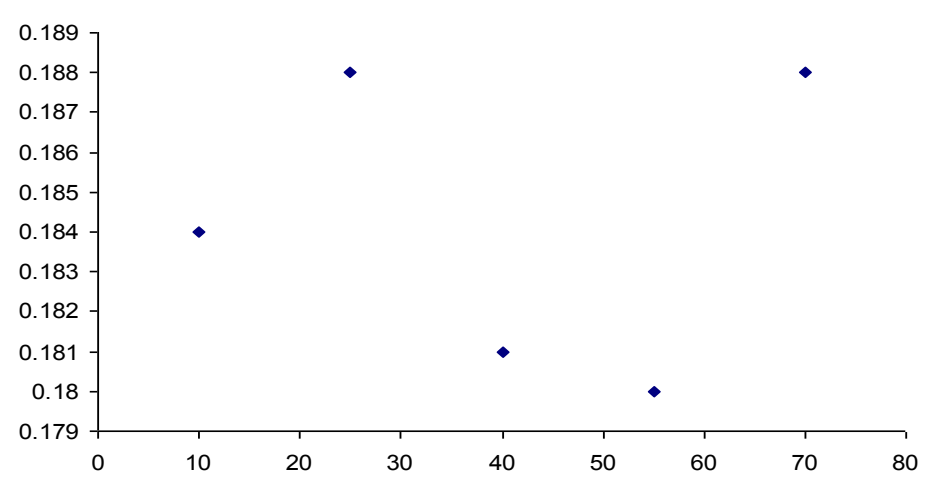

Figure 3. Effect of the average scans per spectrum employed to carry out the instrumental measurements. The study was carried out using a standard with $1 \mathrm{mgg}^{-1}$ concentration and the measurements were obtained working with height values for the $1704 \mathrm{~cm}^{-1}$ with a baseline correction between 1850 and $1550 \mathrm{~cm}^{-1}$. 


\section{Selection of Bands for FTIR Determination of Lorazepam}

In order to choose the best analytical performance of the FTIR determination of lorazepam in pharmaceuticals, different bands and baseline correction criteria were evaluated, as can be seen in Table 1. In every case, it was also considered the use of peak height and peak area absorbance measurements modes.

Table 1. Analytical features of FTIR determination of lorazepam in pharmaceuticals using peak height and peak area with different baseline corrections.

\begin{tabular}{|c|c|c|c|c|c|c|}
\hline $\begin{array}{l}\text { Peak } \\
\text { height, } \\
\mathrm{cm}^{-1}\end{array}$ & $\begin{array}{l}\text { Baseline } \\
\text { correction, } \\
\mathrm{cm}^{-1}\end{array}$ & $\begin{array}{l}\text { External calibration line }{ }^{a} \\
\qquad y=a[\text { lora }]+b\end{array}$ & $\mathrm{R}^{2 \mathrm{~b}}$ & $\%$ R.S.D ${ }^{\mathrm{c}}$ & $\operatorname{LOD}^{d}$ & $\mathrm{LOQ}^{\mathrm{e}}$ \\
\hline 1704 & $1850-1550$ & $\begin{array}{c}\mathrm{y}=(0.1968 \pm 0.0117)[\text { lora }]- \\
(0.0053 \pm 0.0160)\end{array}$ & 0.9981 & 2.652 & 0.04 & 0.13 \\
\hline 1326 & $1425-1273$ & $\begin{aligned} \mathrm{y}= & (0.0716 \pm 0.0114)[\text { lora }]- \\
& (0.00151 \pm 0.0156)\end{aligned}$ & 0.9869 & 2.850 & 0.05 & 0.17 \\
\hline 1130 & $1194-1000$ & $\begin{aligned} \mathrm{y}= & (0.1045 \pm 0.0144)[\text { lora }]- \\
& (0.00736 \pm 0.0196)\end{aligned}$ & 0.9902 & 2.875 & 0.1 & 0.33 \\
\hline
\end{tabular}

\begin{tabular}{|c|c|c|c|c|c|c|}
\hline $\begin{array}{l}\text { Peak } \\
\text { area, } \\
\text { Acm }^{-1}\end{array}$ & $\begin{array}{c}\text { Baseline } \\
\text { correction, } \\
\mathrm{Acm}^{-1}\end{array}$ & $\begin{array}{l}\text { External calibration line } \\
{ }^{a} \mathrm{y}=\mathrm{a}[\text { lora }]+b\end{array}$ & $\mathrm{R}^{2 \mathrm{~b}}$ & $\%$ R.S.D ${ }^{c}$ & $\operatorname{LOD}^{\mathrm{d}}$ & $\mathrm{LOQ}^{\mathrm{e}}$ \\
\hline $\begin{array}{l}1739- \\
1634\end{array}$ & $1850-1550$ & $\begin{array}{c}\mathrm{y}=(6.4277 \pm 0.6161)[\text { lora }]- \\
(0.2771 \pm 0.8406)\end{array}$ & 0.9952 & 6.343 & 0.25 & 0.83 \\
\hline $\begin{array}{l}1358- \\
1297\end{array}$ & $1425-1273$ & $\begin{aligned} \mathrm{y}= & (1.3756 \pm 0.1412)[\text { lora }]- \\
& (0.0087 \pm 0.1926)\end{aligned}$ & 0.9945 & 7.846 & 0.18 & 0.60 \\
\hline $\begin{array}{l}1158- \\
1114\end{array}$ & $1194-1000$ & $\begin{aligned} \mathrm{y}= & (1.6996 \pm 0.1287)[\text { lora }]- \\
& (0.0301 \pm 0.1756)\end{aligned}$ & 0.9970 & 11.572 & 0.21 & 0.70 \\
\hline
\end{tabular}

${ }^{a}$ Calibration curve where $a$ and $b$ correspond to the slop and the intercept, respectively, being [lora] the concentration of loazepam expressed in $\mathrm{mgg}^{-1},{ }^{b}$ Correlation coefficient, ${ }^{c} \%$ relative standard deviation (for five independent measurements) calculated for a standard of $1 \mathrm{mgg}^{-1}$ concentration., ${ }^{d}$ Limit of detection expressed in $\mathrm{mg}$ per $\mathrm{g}$ and calculated using $3 \mathrm{~s}$ criteria, where $s$ corresponds to standard deviation of five measurements of the blank solution. ${ }^{e}$ Limit of quantification expressed in $\mathrm{mg}$ per $g$ and calculated using 10 s criteria, where s corresponds to standard deviation of five measurements of the blank solution.

In terms of sensitivity, taking into consideration the calibration slope values, it is clear that peak area values provide at least one order magnitude better sensitivity than peak height measurements. Data in Table 1 also reports the limit of detection (LOD) and the limit of qualification (LOQ) values and the relative standard deviation (R.S.D \%) found on using the different criteria. As it can be seen several studied conditions provide appropriate characteristics for pharmaceutical analysis.

The band at $1704 \mathrm{~cm}^{-1}$ provides the best precision, sensitivity and limit of detection/quantification values. However, as shown in Figure 2 for sample spectra there is not a shoulder near the selected band and it presents a good symmetry. Because of that, better RSD, LOD and LOQ values and single peak height measurements, we have considered to work with a peak height at $1704 \mathrm{~cm}^{-1}$ and using a baseline correction defined between 1850 and $1550 \mathrm{~cm}^{-1}$. 
Analysis of Commercial Pharmaceuticals

In order to validate the developed FTIR procedure, four pharmaceuticals containing lorazepam were analyzed by both, the FTIR developed procedure and the UV reference method, and results found are summarized in Table 2.

Table 2. Determination of lorazepam in pharmaceuticals by UV and FTIR procedures.

\begin{tabular}{cccccc}
\hline $\begin{array}{c}\text { Pharmaceutical } \\
\text { company }\end{array}$ & $\begin{array}{c}\text { Declared } \\
\text { content } \\
(\mathrm{mg} / \mathrm{tab})\end{array}$ & $\begin{array}{c}\text { FTIR method per tablet } \\
\pm \mathrm{RSD} \%\end{array}$ & $\begin{array}{c}\text { UV method } \\
\pm \mathrm{RSD} \%\end{array}$ & $\begin{array}{c}\text { Relative } \\
\text { accuracy } \\
\text { error\% }\end{array}$ & $\mathrm{t}_{\text {exp }}$ \\
\hline Abidi & 2 & $1.97 \pm 1.27$ & $1.98 \pm 0.30$ & 1.5 & 0.0928 \\
Zahravi & 2 & $1.94 \pm 1.89$ & $1.95 \pm 0.75$ & 2.8 & 0.0296 \\
Loghman & 1 & $0.94 \pm 2.30$ & $0.95 \pm 0.31$ & 6.9 & 0.2664 \\
Kimidaro & 1 & $0.97 \pm 1.26$ & $0.98 \pm 0.74$ & 2.9 & 0.1761 \\
\hline
\end{tabular}

We used t-test for judgment about differences between means of two series of data that result from UV and FTIR methods. The results of t-test are introduced in Table 2. Additional experiments made on spiking real samples with lorazepm amounts from $0.5 \mathrm{mg}$ per tablet provided recovery percentage from 97 to $101 \%$ in the selected conditions. The results are shown in Table 3.

Table 3. Determination of lorazepam in pharmaceutical by FTIR procedure.

\begin{tabular}{cccccc}
\hline $\begin{array}{c}\text { Pharmaceutical } \\
\text { company }\end{array}$ & $\begin{array}{c}\text { Declared } \\
\text { content }^{\mathrm{a}}\end{array}$ & $\begin{array}{c}\text { Spiked } \\
\text { content }\end{array}$ & $\begin{array}{c}\text { Measured } \\
\text { content }\end{array}$ & \%RSD $^{\mathrm{b}}$ & \%Recovery $^{\text {\% Recid }}$ \\
\hline Abid & 2 & 0 & 1.94 & 1.89 & - \\
& 2 & 0.5 & 2.43 & 1.80 & 97.41 \\
Zahravi & 2 & 0 & 1.97 & 1.27 & - \\
& 2 & 0.5 & 2.47 & 1.98 & 99.88 \\
Loghman & 1 & 0 & 0.94 & 2.30 & - \\
& 1 & 0.5 & 1.42 & 2.87 & 98.44 \\
Kimidaro & 1 & 0 & 0.97 & 1.48 & - \\
& 1 & 0.5 & 1.26 & 1.81 & 101.28 \\
\hline
\end{tabular}

${ }^{a} \mathrm{mg}$ of lorazepam per tablet, ${ }^{b}$ Relative standard deviation of the peak height of IR signal at 1704 $(n=5)$.

\section{Conclusion}

The purpose FTIR procedure offers an appropriate alternative to the reference UV method for determination of lorazepam in tablets. The quantification of lorazepam through infrared spectroscopy accomplishes with the requirements of precision, accuracy and linearity as a method for the quality control of pharmaceuticals. Moreover, the method might be categorized within the Category I of analytical methods since is suitable for the quantification of major components of bulk drug substance or active ingredient in finished pharmaceutical products, according to the US Pharmacopoeia (US Pharmacopoeia, 2002). This technique extends the use of a standard IR spectrophotometer, typically used for identification purposes, to the reliable quantification of lorazepam. The present method opens the possibility of applying IR spectroscopy to quantify other active ingredients than lorazepam. 


\section{References}

1. Ghosh J, A Textbook of Pharmaceutical of Chemistry, Chand S and Company ltd., New Delhi, 2003.

2. Bugey A and Staub C, J Pham Biomed Anal., 2004, 35, 555.

3. EC-U.S. Mutual Recognition Agreement sectoral annex for pharmaceutical good manufacturing practices (GMPs). http://www.fda.gov/oia/ecmutual.htm.

4. Pistos C and Stewart J, J Pharm Biomed Anal., 2003, 33, 1135.

5. Borrey D, Meyer E, Lambert W, Van Peteghem S, Van Peteghem C and De Leenheer A P, J Chromatogr B, 2001, 765, 187.

6. Borrey D, Meyer E,Lambert W, Van Peteghem S, Van Peteghem C and De Leenheer A P, J Chromatogr A, 2001, 910, 105.

7. Lee X P, Kumazawa T, Sato J, Shoji Y, Hasegawa C, Karibe C, Arinobu T, Seno H and Sato K, Anal Chim Acta, 2003, 492, 223.

8. Pichini S, Pacifici R, Altieri I, Palmeri A, Pellegrini M and zuccaro P, J Chormatogr $B, 1999,732,509$.

9. Monzon L M A and Yudi L M, J Electroanal Chem., 2001, 495, 146.

10. Nevado J J B, Penalvo G C and Calderon M S P, J Chromaogr B, 2002, 773, 151-158

11. De Julian J V and De la Guurdia M, Can J Spectrosc., 1990, 35, 44-50.

12. USP (United States Pharmacopoeia, $30^{\text {th }}$ revision),

13. Moros J, Garrigues S and De La Guardia M, J Pharm Biomed Anal., 2007, 43, 1277.

14. Lin-Vein D and Colthu N, Grasselli W G, Infrared and Raman Characteristic Frequencies of Organic Molecules, Academic Press, London, England, 1991. 


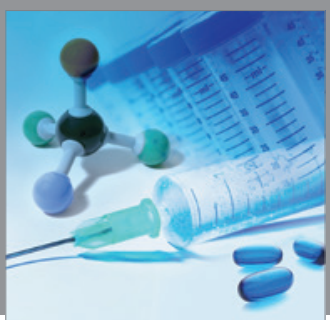

International Journal of

Medicinal Chemistry

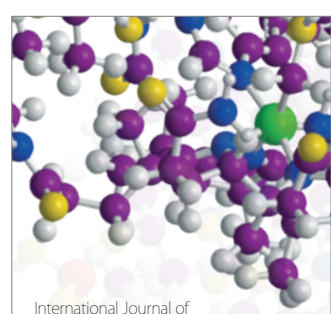

Carbohydrate Chemistry

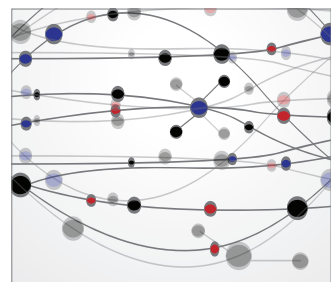

The Scientific World Journal
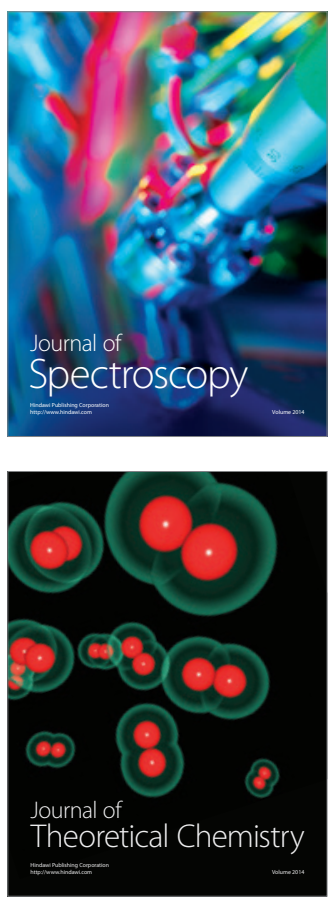
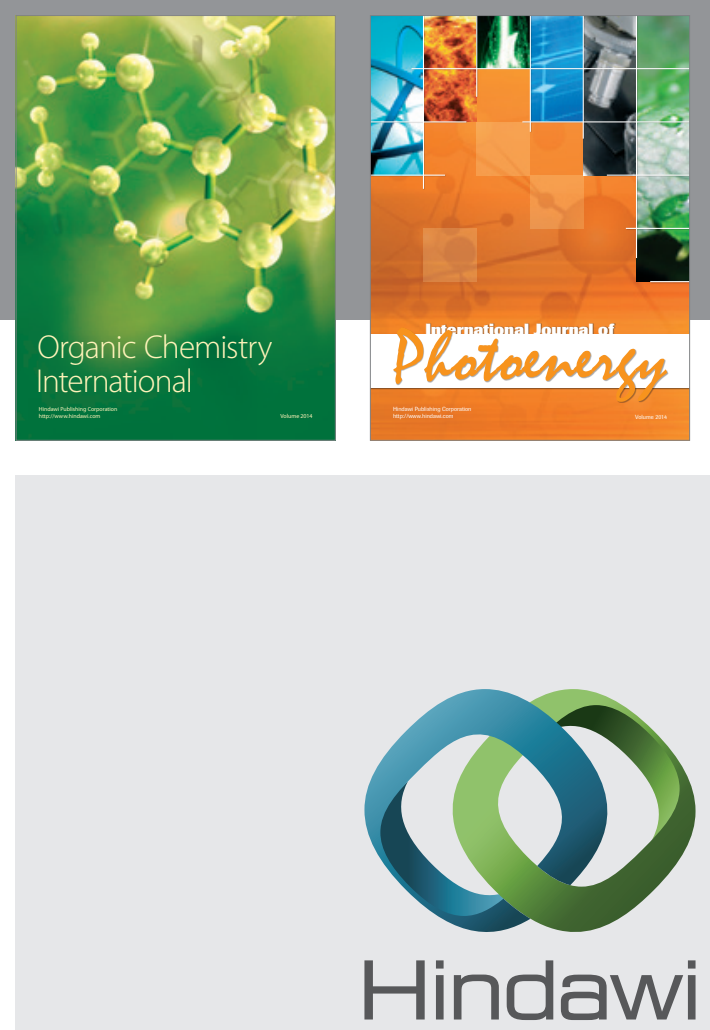

Submit your manuscripts at

http://www.hindawi.com
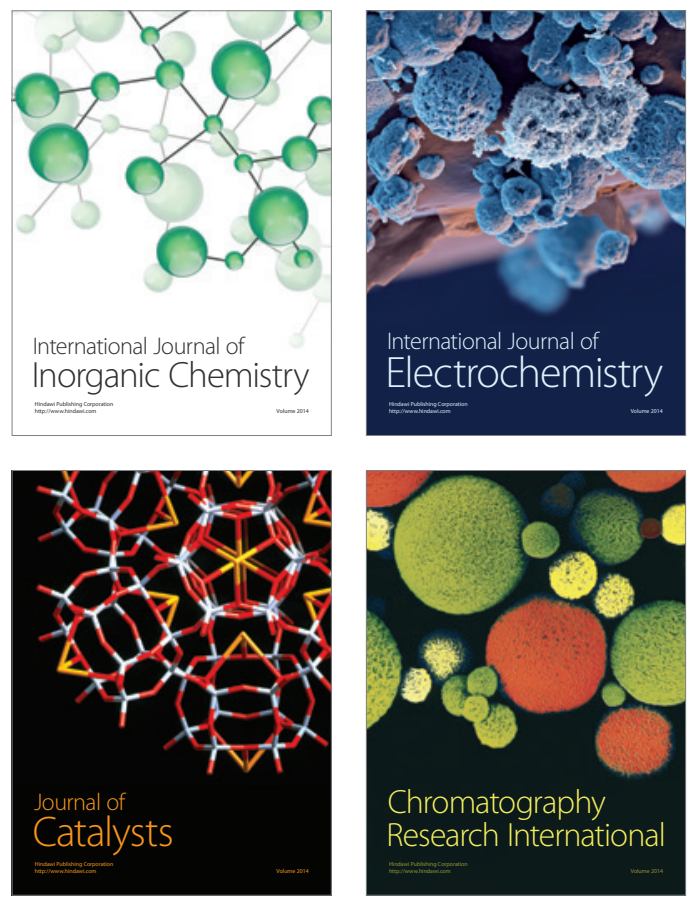
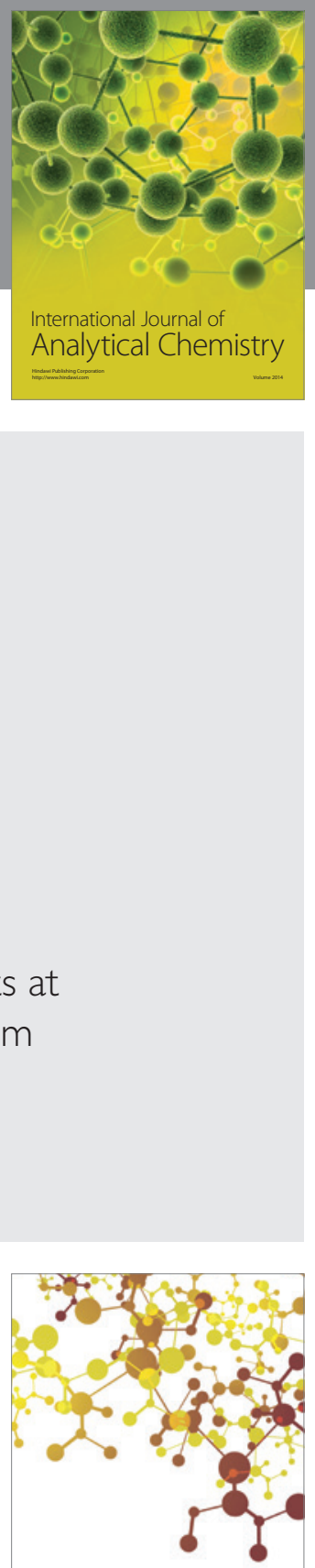

Journal of

Applied Chemistry
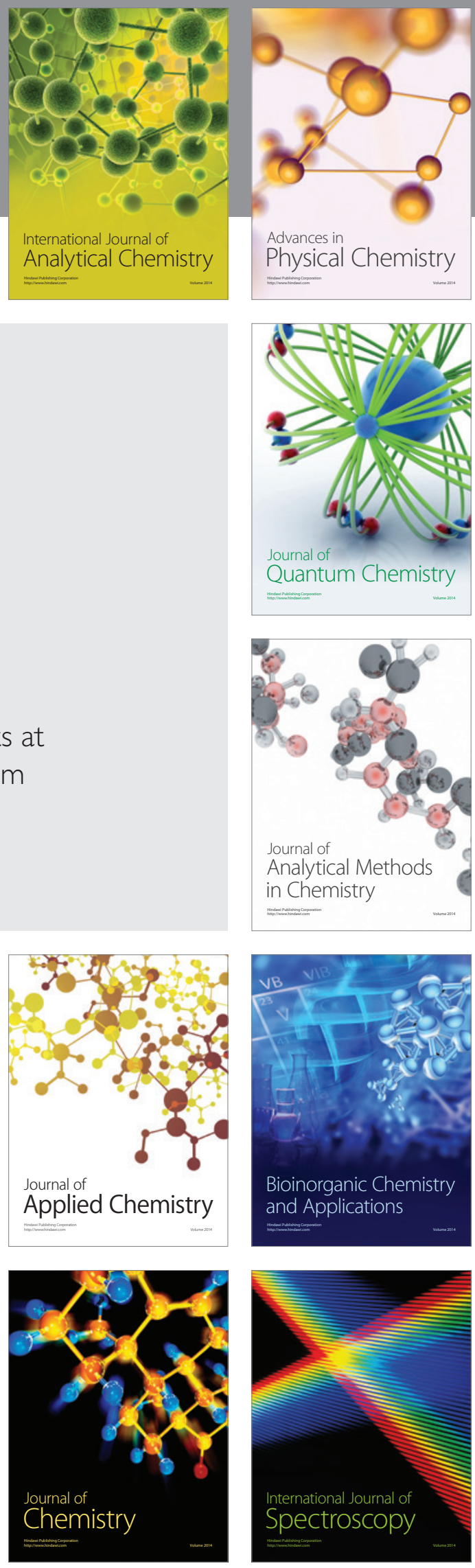